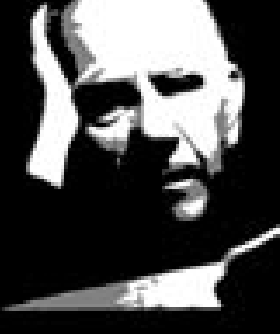

\title{
Uma amizade serena: Erico e Herbert Caro
}

\section{"[...] concordo com os críticos: não sou profundo.} Espero que me desculpem"1.

\section{ANTONIO DIMAS}

é professor de Literatura Brasileira da FFLCH-USP.

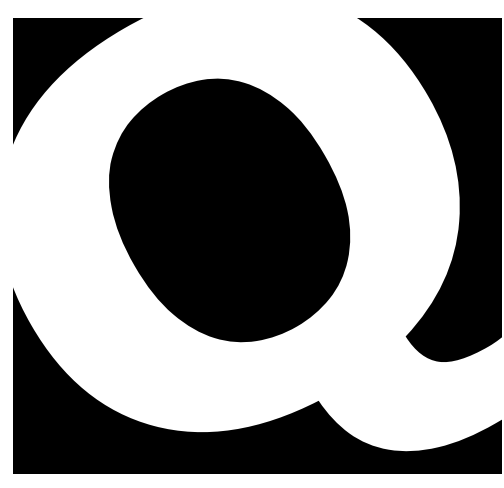

uando se fizer uma história das

relações fraternas entre alguns

intelectuais brasileiros, certos

pares, por causa de seus fortes

vínculos, ocuparão lugar visí-

vel nessa modalidade que só enriquece a história da cultura.

Em termos brasileiros, não po-

dem ser ignoradas algumas parcerias intelectuais que foram se urdindo ao longo do tempo e que, de uma forma ou de outra, cimentaram trajetórias e produziram resultados, ora discretos, ora mais aparentes.

Sem hierarquizar, classificar ou categorizar, vêm à baila determinadas convivências que poderiam muito bem ser consideradas como substanciais para o desenvolvimento e a consolidação 
progressiva de nosso sistema intelectual. Através da troca de cartas constantes, reconhecemos alguns pares decisivos nesse processo simultâneo de auto-revelação e de projeção de desejos comuns, eventualmente individuais, eventualmente coletivos.

Tomando como limites cronológicos os cem anos entre 1880 e 1980, não exige esforço desmedido nos lembrarmos de pares como Nabuco \& Machado, Oliveira Lima \& Nabuco, Nabuco \& Graça Aranha, Euclides da Cunha \& José Veríssimo, Gilberto Freyre \& Oliveira Lima, José Lins do Rego \& Gilberto Freyre, Tristão de Athayde \& Jackson de Figueiredo, Monteiro Lobato \& Godofredo Rangel, Mário \& Bandeira ou Mário \& Drummond, Clarice \& Lúcio Cardoso ou Clarice \& Fernando Sabino, Paulo Leminski \& Régis Bonvicino.

As cartas trocadas por essa gente, hoje publicadas com maior ou menor requinte editorial, deixam-nos visualizar um ativo processo cultural em construção, cujos limites, regras, sonhos, arrufos, azedumes, incoerências e contradições são expostos de forma desabrida e sem retoque. Por meio delas, sabemos de projetos históricos, políticos, diplomáticos, poéticos, científicos que vêm moldando o mapa ideal e real deste país.

O grau de autocontrole na troca dessas cartas é variável e depende da personalidade de cada um, é claro. Um dado como esse - o do autocontrole - já pode servir como índice para a avaliação das temperaturas individuais, bem como da auto-imagem que cada um cultiva e que quer ver projetada no futuro.
Alguns são despachados e não se preocupam com a censura; outros são falsamente humildes, mas de suas letras escorre a vaidade. Há aqueles que não disfarçam o sentido de hierarquia e há os que se aninham na conveniência do aprendizado permanente. Uns posam; outros narram, simplesmente. Há os que pontificam e os que se fecham; há os que contam e os que se abrem. Aqueles escrevem de olho no futuro; estes, de olho no presente. Aqueles miram sua autobiografia; estes vivenciam-na. Para os que posam, as emoções devem estar sob controle rígido, porque o quadro não pode ficar borrado e suas linhas precisam manter definição e clareza; para os que contam, as emoções se imiscuem, se atropelam e não lhes importa se o desenho saiu torto ou se o pincel escorregou.

$\mathrm{Na}$ linha do despautério e da falta de sanção, lembramos as cartas ardentes, escatológicas e até mesmo coprológicas de James Joyce para sua mulher Nora Barnacle. Ou as exuberantes de Paulo Leminski para Régis Bonvicino, plenas de poesia e de desejo novo. Como Flaubert, o poeta de Curitiba não se cansa de expor suas teorias poéticas, sem que isso signifique solenidade e pompa contínuas, porque uma linguagem desataviada e sobrecarregada de efeitos gráficos quase irreprodutíveis quebra, de forma constante, a fluência do discurso linear e magisterial.

$\mathrm{Na}$ linha oposta - aquela em que o superego fala alto, as regras sociais são mais imperiosas, o cabelo não se desmancha, nem o rosto se afogueia - está uma carta clássica de Joaquim Nabuco, na qual se 
rompem anos de amizade com Oliveira Lima. Não se sabe direito o que provocou essa resposta elegantíssima de Nabuco, porque não se conhece a carta de Oliveira Lima, mas pode-se imaginar o tamanho da ofensa através da suprema cortesia e superioridade com que a responde o nosso embaixador em Washington, naquela época. As entrelinhas da carta de Nabuco permitem-nos imaginar que Oliveira Lima abusara da amizade e da franqueza. Didático e sentencioso, Nabuco responde-lhe de modo altivo e ainda recorre a uma anedota sumária, que melhor ilustrasse o sentido de sua reprimenda:

"Há tempo um patrício nosso surpreendiase de me achar com o cabelo todo branco, tendo eu sido seu colega de Academia. $\mathrm{O}$ dele estava muito mal pintado, mas eu nada lhe disse. Era somente uma questão de vaidade, mas mesmo nessa me doeria tocar. E não éramos amigos".

E logo depois da historinha para esclarecer, vinha a frase torcida, dita de cima para baixo:

“'O gosto de dizer 'verdades' aos que nos mostram afeição não prova maior sinceridade do que a atenção em nunca os melindrar, e em geral os que se gabam daquele predicado escolhem os amigos com quem possam ser francos".

Mas a estocada final estava reservada para o fim. Vinha soberana e impiedosa, jogando toda a culpa sobre Oliveira Lima, a quem Nabuco atribuía a responsabilidade exclusiva pelo desastre final de longa amizade: "Deixo as demais farpas da sua carta ao esquecimento, pois quero que a nossa correspondência acabe, ficando todos os agravos dela à sua conta" (Nabuco, 1949, v. 2. p. 250).

Entre as cartas deliberadamente licenciosas como as de Joyce, as arrojadas como as de Leminski, as doutrinárias de Flaubert ou as contidas como as de Nabuco, podemos situar as de Erico Verissimo num patamar diferenciado e até certo ponto homólogo a seu romance, eqüidistante da reviravolta formal e do continuísmo narrativo. Porque suas cartas contam e conversam, não ensinam, nem posam.

Trata-se de arquivo muito precioso, muito rico e do qual vai borbulhar, com certeza, uma quantidade enorme de trabalhos em torno de Erico, depois de processados todos os seus documentos com a cautela técnica que exigem. São caixas e mais caixas de cartas de natureza diversa, mais extensas ou mais curtas, mais formais ou menos formais, ora bem-humoradas, ora planas, mas todas capazes de fornecer, fragmento por fragmento, um retrato mais amplo e mais detalhado desse escritor que implantou o Rio Grande do Sul de forma definitiva e irreversível no mapa literário e cultural brasileiro.

Por meio dessa massa enorme de correspondência, desenha-se um Erico que reconfirma muito daquilo que a crítica especula através de penosas interpretações literárias. Vasculhando essas caixas e bisbilhotando cartas de forma aleatória, começa a crescer diante de nós uma figura cada vez mais concreta, palpável, incerta, amorosa, solidária e soterrada de incansável trabalho contínuo, destinado a várias direções simultâneas, das quais ele se subtraía com habilidade para dedicar-se aos amigos e afagar seus familiares. É um Erico multifuncional e polivalente que se ergue daquelas cartas. Um Erico também arlequinal, cujas relações pessoais não se subordinavam à docência informal, nem temiam a opinião política, mesmo que solitária em contexto áspero. Permeia suas cartas uma aflição serena, indócil, nada panfletária, muito mais do tipo teimoso e murmurante. Nada de enfrentamentos ostensivos e barulhentos; tudo a favor da persistência prolongada, que busca a harmonização, sem prejuízo da qualidade e da dignidade humanas.

Multiplicam-se os exemplos que convalidam esse temperamento, e um deles, escolhido de forma deliberada, traz muita água para esse moinho da tolerância exercitada com obstinação e firmeza. De forma deliberada, porque na outra ponta dessa correspondência com Erico situa-se uma figura maravilhosa, um intelectual bem 
dotado e que fora escorraçado pela intolerância nazista, em nosso benefício.

Desculpem-nos a crueza do paradoxo, mas é difícil evitá-lo. Cada vez nos convencemos mais que abarbaridade nazista foi-nos benéfica; que esse momento de desatino e de sandice da portentosa cultura alemã comprova duas hipóteses, entre várias outras. Uma, a de que o processo cultural não é necessariamente evolutivo e cumulativo, pois que está sujeito a lapsos aterrorizantes como o que acometeu a Alemanha do Terceiro Reich. A outra, a de que a caça à inteligência local resultou em substancial alavancamento das condições intelectuais das Américas, haja vista ôexodo maciço de judeus que, diante de nova ameaça genocida, repetiram ocaminho dos ibéricos que nos descobriram e que nos trouxeram os ingredientes de uma cultura européia em plena expansão.

Para outros pontos desta imensa América encaminharam-se profissionais de alto coturno, prontos a colaborar com a nova realidade que os acolhia, mesmo que sob o domínio do medo e da dor. Para este país, vieram vários outros, não menos dispostos a fazer disso uma alternativa existencial e intelectual, mesmo que sob a angústia do reinício, em idade madura. E por causa do anátema que pesou sobre eles e que os deslocou de forma atroz, lucramos. Com Otto Maria Carpeaux, ganhamos a monumental História da Literatura Ocidental e um crítico de envergadura; com Anatol Rosenfeld, reforçamos uma crítica teatral já bem avançada e, de quebra, recentemente, incorporamos suas crônicas sensíveis, em que se narram as aventuras de enfrentamento de um oeste brasileiro em expansão(Rosenfeld, 2003); com Vilém Flusser alargou-se nossa especulação filosófica, que chegou a se sentir incomodada por causa de seu pensamento "genuinamente subversivo, tão livre de todos os clichês", nas palavras de Sérgio Paulo Rouanet (apud Kestler, 2003, p. 97). Esses homens de pensamento são apenas a ponta de um iceberg, que começa a ser descongelado de forma criteriosa por Isabela Kestler, em ensaio dedicado aos “escritores de fala alemã durante a época do nazismo” (Kestler, 2003, p. 97).
No meio dessa massa de foragidos, uma figura respeitável escolheu Porto Alegre como sua querência, fiando na possibilidade de que lá poderia retomar sua trajetória interrompida de forma abrupta. Aos 29 anos e com um diploma de Direito nas mãos, chancelado pela Universidade de Heidelberg, desembarcou na beira desse mesmo Guaíba o cidadão Herbert Caro, nascido em 1906, em Berlim, e que veio a falecer em Porto Alegre em 1991, com 85 anos, 56 dos quais a serviço da lexicologia bilíngüe e da tradução de clássicos alemães para o nosso português.

Sua trajetória rica, ainda em fase de reconstrução detalhada, destinou-o à beneficência, à solidariedade grupal, à vida comercial, ao cultivo da música clássica e, o que nos interessa aqui, ao convívio intelectual, a partir do momento em que ingressou na "Sala dos Tradutores" da Editora Globo, onde veio a conhecer outra ponta deste relato, preocupado com parcerias intelectuais ${ }^{2}$. Foi na Editora Globo que Herbert Caro e Erico Verissimo se cruzaram e deram início a um companheirismo pessoal e intelectual dos mais carinhosos e dos mais respeitáveis.

Cópias de cartas de Erico a Herbert recheiam caixas do Acervo Literário de Erico Verissimo e, mesmo sem termos tido acesso àquelas que Herbert enviou a Erico, é possível esboçar um quadro altamente positivo desse relacionamento, uma vez que a amenidade que dessas se libera permitenos confiar na boa disposição anímica dos dois correspondentes.

Com os dados que Flávio Loureiro Chaves (1996) oferece em seu Erico Verissimo, o Escritor e seu Tempo, fica-se sabendo que o autor de O Tempo e o Vento passou sua terceira temporada nos EUA entre 1953 e 1956, na condição de diretor do Departamento de Assuntos Culturais da União Pan-Americana, sucedendo a Alceu Amoroso Lima.

É nesse período que nos detemos e dele retiramos algumas cartas, orientando-nos pelo critério do relacionamento entre Erico e o refugiado berlinense, o "meu caro Caro", como insistia em chamá-lo um Erico dis-
2 Essas informações biográficas preliminares sobre Herber Caroforam extraídas de matéria jornalística intitulada "Todas a aces de Herbert Caro", ass. nada por Rosanal Candeloro publicada na Folha de S. Paulo em $7^{\circ}$ de janeiro de 1995 
tante, à beira de um outro rio, o Potomac. Entre esse rio que banha Washington, D. C., e o Guaíba, subiram e desceram inúmeras mensagens, marcadas pelocarinho, afáveis, interessadas, informativas e que, de modo geral, cuidavam da vida pessoal, da música, do teatro, de leituras, de cinema, de viagens profissionais, dos afazeres cotidianos, da necessidade de notícias, de pequenos desencontros e vaidades presenciadas por Erico naquele órgão de alcance internacional. Um lugar onde não deveria escassear a disputa por interesses imediatos e nem sempre muito nobres, sobretudo se nos lembrarmos de que se tratava de um organismo sediado no centro da política norte-americana e onde se acotovelavam funcionários de diversas procedências latino-americanas.

Da leitura de trechos dessas cartas, o que primeiro salta à vista é a intensa programação de viagens a que Erico estava submetido, como decorrência do cargo que ocupava, e dentro da qual era preciso abrir clareiras a socos, fosse para os artigos rápidos, fosse para a correspondência particular, fosse ainda - esperança remota! - para o ofício de romancista. Exemplos fragmentários, retirados desses anos 50, não deixam dúvida sobre essa atividade intensa, de um vai-e-vem incessante. Em outubro de 1953, Erico conta:

“Andei por Chicago a fazer conferências... Mais tarde fui a Philadelphia, onde falei no Art Alliance. No dia seguinte falei na Universidade de Delaware. E agora aqui estou, depois de haver escrito um review para o New York Book Review sobre Amazon Town, de Wagley..." (30/out./1953; ALEV 02a 0055-1953).

Pouco antes de embarcar para Caracas, em missão oficial, Erico ainda tem tempode relatar a Herbert Caro sua última viagem de "mais de 10.000 quilômetros" por território norte-americano:

Como o processamento dessa documentação epistologrática encontra-se ainda em fase preliminar, preferimos utilizar a data da carta, se explícita, e a sua numeração individual como critério de referência e de sua localização. dias bonitos. Em Colorado encontrei um céu lírico, parecido com o de Porto Alegre, e um pôr de sol tão belo quanto o nosso. [...] As cidades que visitei: Albuquerque, Tucson, Los Angeles, San Francisco, Berkeley, Oakland, Eugene, Seattle, Denver, Colorado Springs, Kansas, St. Louis progridem fabulosamente, são muito confortáveis mas geralmente sem graça, sem imprevisto, sem pitoresco" (11/ fev./1954; ALEV 02a 0059-1954).

$\mathrm{O}$ viajante infatigável atende a todos e jamais se nega às solicitações de uma sociedade aparentemente curiosa, mas sempre muito satisfeita consigo mesma e que até hoje insiste em se informar apenas como álibi samaritano. Da perspectiva do informante, no entanto, a curiosidade permanente, o olhar agudo para os detalhes, a perspicácia em capturar a metonímia do comportamento, das cores, das falas, da vivacidade e do inesperado são instrumentos sempre alertas, que haverão de se deliciar quando em visita a uma cultura vizinha, de perfil inteiramente diferente. Frente a um espaçoe a uma história que se fazem bem ali na sua frente, fartos de imprevistos, de cores, de movimentos e de contatos humanos informais, alvoroçase o homem calmo de Cruz Alta, afrouxa a gravata o diretor do Departamento de Assuntos Culturais da União Pan-Americana, relaxa o conferencista experiente e bem-articulado. $\mathrm{E}$ porque se torna menos austera a atitude do viajante, sairá lucrando aquele amigo distante, que ficara encerrado entre as paredes da Livraria Americana de Porto Alegre. Maravilhado com o que vira no México, Erico conta para Herbert Caro, em primeiríssima mão, as notícias de uma viagem que, um dia, virariam livro:

"Voltei do México há três dias... [...] Foi uma viagem interessantíssima da qual sairá um livro. Creio que tenho material mais rico e colorido do que o dos Gatos Pretos. [...] Passamos vinte dias na capital. [...] Vimos igrejas fabulosas. Apaixonei-me pelo barroco mexicano. Em Taxco nos hospedamos na Casa de Humboldt, onde o barão viveu quando por lá andou. [...] Retretas na praça, festas de igreja, com foguetes, prateiros, 
santeiros; pura Idade Média nas igrejas. Que país dramático! A cor dos tapetes e rebozos pode ser viva e berrante, mas a cor essencial da terra e da alma mexicana é parda. E a História do país, que romance trágico! As crianças com seus olhos de veludo úmido e terno impressionam. Eos burricos também" (26/jun./1955; ALEV 02a 0079-1955).

Se no relato acima temos um Erico atento ao volume, às formas, ao movimento, ao som, à contradição das cores e ao misturado da impressão tátil, sem hierarquizar pessoas e animais, agrupando tudo sob a categoria da coisa viva, atraente e descontínua, capaz de produzir uma história de acento trágico, ficaria fácil acusá-lo de preocupado tão-somente com o pitoresco e com o superficial, acusá-lo de viajante novidadeiro à cata de relatos reluzentes, mas sem tutano.

Longe de pretender mergulho fenomenológico e analítico na alma mexicana, no entanto, o livro que resultou dessa viagem foi publicado em 1957, chama-se México e apareceu bem depois dos dois Gatos, que são de 1941 e 1946. Mais que narrativa obcecada com estruturas políticas e sociais, na qual se condenam as injustiças óbvias, seu discurso explícito é o de quem permite que o ziguezague da condição humana aflore a partir da visualização dos tipos descritos.

Exemplo dessa técnica de abordagem indireta da realidade é o de uma visita à residência de um nobre alemão, que também buscara o exílio por causa de Hitler. Ao narrá-la, sobrecarrega-se a imaginação de Erico, que a sobrepõe à frieza da simples descrição. Diz o narrador:

“O quarto me encanta. Com indiscrição muito própria dum romancista, vou olhar de perto o retrato que está sobre a mesinha de cabeceira, ao lado da grande cama de ferro. Vejo uma mulher com feições de menina, intensos olhos de tísica, a encarar o fotógrafo com um sorriso triste. Reconheço a morte na face pálida, na mirada febril. Deve ser a primeira esposa do barão. Possivelmente esta é a cama em que morreu" (Verissimo, 1957, p. 213).
Os apontamentos de viagem, escritos por quem registrou "diálogos com índios, condutores de táxi, gente da rua”, recuperam sua vitalidade graças à intromissão deliberada da emoção na reconstituição do evento, procedimento de que não abre mão o romancista apegado ao ofício, mesmo que essa restauração se faça em cima de experiência recente. Como ensinaram alguns realistas do século XIX, o romancista não abandona a caderneta de anotações, nem nela se pendura, dependente, no processo de recuperação da experiência. Porque aoreconstruiro percurso da viagem real, seu compromisso nãoé coma objetividade ilusória daquiloque presenciou, mas com o conjunto de suas experiências pessoais e culturais anteriores, amalgamadas, plasmadas e introjetadas naquelas do tempo recém-ocorrido.

Em rememoração que confunde, de propósito, momentos distintos do passado, o viajante reconfigura tempos e espaços, aniquila seus limites, desmancha a distância entre o sítio imaginário e o sítio visitado, acabando por criar uma terceira realidade, cuja força advém do filtro pessoal feito de experiência acumulada. Essa é a impressão que esse viajante contumaz nos provoca quando relembra o primeiro contato com a casa do barão refugiado na capital mexicana. Ao baterem na porta de sua casa, Erico e seu acompanhante são atendidos por uma "menina esgalgada, de seus treze anos, muito alva, de olhos claros, cabelos cor de palha, em longas tranças" (Verissimo, 1957, p. 212). Encantado de chofre com a delicada figura infantil, as lembranças atropelam-se, embaralham-se, fundem-se e confundemse, arrancando o leitor de um tempo presente e de um espaço concreto para jogá-lo longe, em direção a um outro continente, que se levanta diante de nós não por força de uma descrição realista, mas por intermédio de um desenho de sedimentação nitidamente literária. Depois de ser cumprimentado pela "menina esgalgada", que lhe abrira a porta, o narrador suspende o presente, perde-se na memória e observa:

“A guria tem voz de água e vento. Deve chamar-se Gretchen. O pai? Moleiro. A 
mãe? Fiandeira. Quando não está na escola, a rapariguita é guardadora de patos. Lá vai ela, varinha na mão, descalça pelo campo, tangendo patos brancos de bicos e patas amarelos, que em fila indiana caminham para o lago. O vento, guardador de nuvens, tange no céu grandes rebanhos de algodão.

Como é que tantas imagens podem passarnos pela mente numa simples fração de segundo?" (Verissimo, 1957, p. 212).

A pergunta pode parecer retórica e é. Recurso corriqueiro de fingir modéstia, que não desmerece, antes sublinha a qualidade da recordação. Mas se nos voltarmos à carta que um dia esteve nas origens dessa narrativa de viagem, observaremos que a simultaneidade das ações já fazia parte das primeiras impressões de Erico. Ao encerrar o tópico da viagem, antes de passar para outro assunto, Erico alinha um conjunto de elementos de tênue conexão interna, como se fossem itens de um memorandum a ser reutilizado num futuro próximo. Tem-se a impressão de que a carta para Herbert Caro adquire dupla funcionalidade: de um lado, a notificação habitual de quem precisa e quer se comunicar; de outro, o apontamento básico de quem não quer deixar esvair-se da memória a oportunidade do fato. E, no esforço de apreensão e de retenção, em frase curta que não pode se estender para não se perder, nosso homem em Washington compacta a notícia através de frase na qual se contam três blocos informativos, cada um deles dando conta de situações simultâneas e pontuais: "Voltei com um caderno cheio de notas, a pele queimada e cheio dum desejo de escrever sobre esse estranho país de montanhas, vulcões, índios místicos, bandidos e visionários" (26/jun./1955; ALEV 02a 0079-1955).

Em tão poucas cartas, recolhidas de forma quase aleatória, empilham-se assuntos e mais assuntos, que, não fosse o tempo limitado e de bom grado aceito, nos fariam preencher de modo impertinente esta oportunidade. Porque, insaciável de curiosidade factual e antropológica, Erico não perde nada, vasculha tudo e aproveita de forma mágica o seu tempo de aparência mais espichada que nossas míseras 24 horas cotidianas. Entre sua casa nos arredores da capital norte-americana e seu escritório na União Pan-Americana interpõe-se um universo de novidades que sua curiosidade não negligencia. Acompanhado de Mafalda nos concertos, nos cinemas, nos teatros e nos restaurantes; atencioso com o aprendizado da filha nos palcos e com o do filho, que prefere a música; sozinho em suas peregrinações por universidades, associações de classe, clubes de senhoras ou instituições culturais; receptivo sempre aos visitantes oficiais da cidade ou àqueles que por ali estão apenas de passagem, Erico desdobra-se em gentilezas, estica-se em compromissos, mas ainda acha tempo para refugiar-se na sua música clássica, de que dá conta sistemática ao seu amigo Herbert Caro, como se estivesse se apresentando diante de um professor exigente. Ao longo das cartas, são inúmeras suas referências a concertos, à aquisição de novos discos, ao prazer de ouvi-los, à ginástica para que sua compra não sacrifique o orçamento doméstico. Em dado momento, num repente de desinibida alegria juvenil, Erico comunica que acabara de se tornar proprietário - pela quantia de 700 dólares - de uma alta-fidelidade, de som tão perfeito que tornava irreconhecível seus próprios discos. É tamanha a excitação com o presente que se dera, que sua descrição não cabe dentro da palavra, muito pequena para dar conta da magnitude do acontecimento. No afã de substituí-la e afoito para transmitir ao amigo o prazer da novidade tecnológica, o escritor abandona-a e rabisca a cena com detalhes até ociosos, mas suficientes para desfazer o verismo do desenho, nele incutindo sua nota de humor:

A música funciona como elo inegável entre ambos. Familiarizado com a cultura musical de Caro, Erico presta-lhe tributo constante ao comentar suas aquisições, mas sempre com tato e delicadeza para não parecer perdulário ou exibicionista. Usufruindo de condição favorável que lhe permitia acesso fácil ao mercado discográfico norte-americano, o escritor sondava 
de forma cautelosa sobre o acerto de suas escolhas, em sutil atitude respeitosa de quem se comportava como aprendiz.

Mesmo sem acesso às cartas de Herbert Caro, por enquanto, não seria temerária a impressão de tratamento fraterno e respeitoso entre os dois, porque o tom sereno das cartas de Erico permite-nos essa inferência. Porque em nenhum momento percebe-se a ameaça de tom professoral ou de hierarquias disfarçadas. Em vez disso, o trato ameno, a confiança recíproca, a guarda baixa, a emulação relaxada e despretensiosa, capaz até de permitir confissões sobre crenças e técnicas poéticas.

Assim que começa a receber recortes das crônicas de Herbert, aquelas que mais tarde viriam a se tornar conteúdo do precioso Balcão de Livraria, livro bem-humorado, bem escrito, inteligente e que anda exigindo reedição, Erico cumprimenta o autor por ter descoberto "um veio de ouro" (15/dez./1953; ALEV 02a 0057-1953). E acrescenta: "Debaixo daquele título despretensioso, cabe um mundo".

Mais tarde, em outra carta, a despretensão alheia provoca uma profissão de fé que, se tivesse se tornado pública naquela ocasião, teria economizado muita tinta da crítica e muita restrição disfarçada por eufemismos, um dos traços reiterados da crítica erudita que não dá o braço a torcer para esse escritor que sempre se declarou um simples "contador de histórias".

Ao comentar com Herbert que fizera

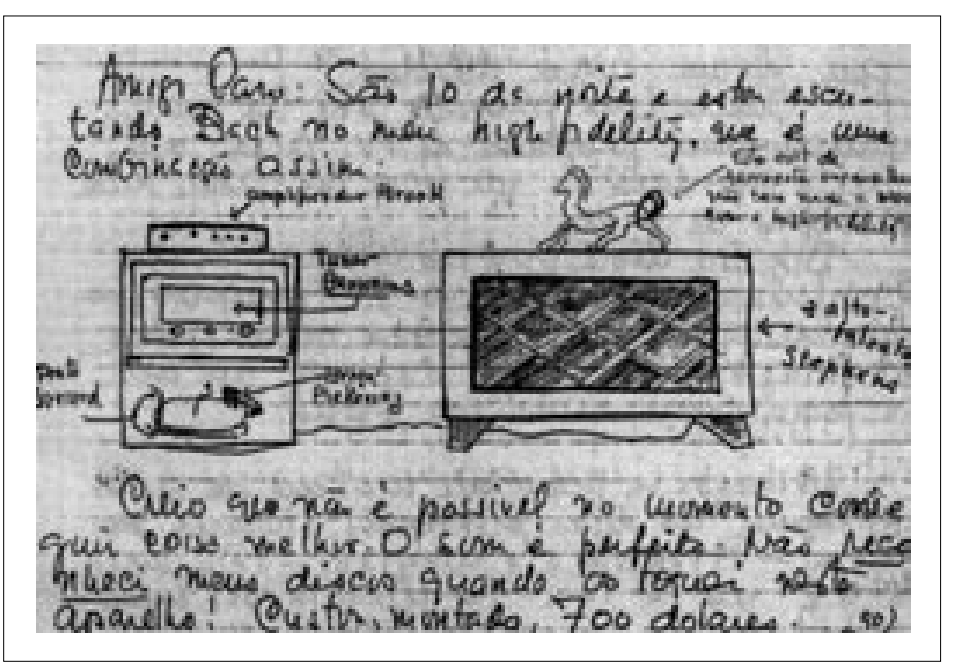

amizade com o dono de uma livraria em Washington e que isso lhe dera a chance de compra antecipada de Fable, livro de contos de Faulkner a ser lançado no mês seguinte, Erico confessa: “Comecei a ler. Que dureza, amigo Caro! O homem é intransitável. Não sei que necessidade terá de complicar tanto as coisas. É penoso, verdadeiro trabalho braçal, vencer uma página desse escritor" (15/jul./1954; ALEV 02a 0065-1954).

Essa recusa tranqüila, sem pompa e sem aflição, sumaria muito bem o comportamento narrativo de um escritor brasileiro que nunca se abalou com o foguetório dos centros urbanos maiores, e que preferiu o caminho de uma simultaneidade paradoxal: um caminho solitário e solidário, em ziguezague constante entre as colinas suaves da sua Petrópolis querida e o mundo aberto de sua itinerância imperturbável.

\section{BIBLIOGRAFIA}

CHAVES, Flávio Loureiro. Erico Verissimo, o Escritor e seu Tempo. Porto Alegre, Escola Técnica da UFRGS, 1996.

KESTLER, Isabela Maria Furtado. Exílio e Literatura: Escritores de Fala Alemã durante a Época do Nazismo. São Paulo, Edusp, 2003.

NABUCO, Joaquim. Cartas a Amigos. Coligidas e anotadas por Carolina Nabuco. São Paulo, Instituto Progresso Editorial, 1949.

ROSENFELD, Anatol. Off Road. Edição especial organizada por J. Guinsburg, Nanci Fernandes e Plínio Martins Filho em homenagem aos 30 anos de sua morte. São Paulo, USP/Pró-Reitoria de Cultura e Extensão/Edusp/Perspectiva, 2003.

VERISSIMO, Erico. México: História duma Viagem. Porto Alegre, Globo, 1957.

. A Liberdade de Escrever: Entrevistas sobre Literatura e Política. Org. Maria da Glória Bordini. Apres. Luis

Fernando Verissimo. Porto Alegre, Editora da UFRGS/Prefeitura de Porto Alegre/EDIPUCRS, 1997. 